\title{
O CAMPO UNIVERSITÁRIO PORTUGUÊS Transformações e disputas entre 1988 e 2015
}

\author{
João Mineiro \\ CRIA-IUL, Socius-ISEG, Lisboa, Portugal
}

Resumo Este artigo analisa o campo universitário português entre 1988 e 2015, com base no discurso de 18 antigos e atuais reitores e dirigentes estudantis e nas mudanças sociais, económicas e políticas deste período. Primeiro, descrevem-se aquelas que, segundo os agentes, constituem as dez principais transformações das instituições universitárias. Depois, examinam-se os principais dissensos suscitados por essas transformações. Por último, partindo destas transformações e dissensos, analisamos a universidade enquanto campo, isto é, enquanto subconjunto relacional do espaço social, estruturado através de posições e disposições, onde os agentes lutam pela posse de um capital específico e que tem uma autonomia relativa na relação com o poder político e económico.

Palavras-chave: universidade, campo, campo universitário, neoliberalismo, ensino superior

Abstract This article analyses the Portuguese universities field between 1988 and 2015, laying its foundations on the discourses of 18 current and former deans and leading students and in the social, economic and political changes in that period. At first, we will describe those that, according to social agents, constitute the ten main transformations of the university institutions. Then, we will examine the main points of contention raised by these transformations. Lastly, departing from these transformations and points of contention, we analyze the University as a field, this is, as a relation subset of social space, structured through the positions and dispositions, where the agents struggle for the possession of specific type of capital and that has a relative autonomy in relation to the political and economic power.

Keywords: university, field, university field, neoliberalism, higher education.

Résumé Cet article porte sur le champ universitaire portugais entre 1988 et 2015, sur la base du discours de 18 anciens et actuels doyens et leaders étudiants et aussi des changements sociaux, économiques et politiques de cette période. D'abord, on décrit celles qui, selon les responsables, sont les dix principales transformations des universités. Ensuite, on examine les principaux désaccords soulevés par ces transformations. Enfin, en partant de ces changements et désaccords, nous analysons l'université comme un champ, ça veut dire, en tant que sous-ensemble relationnelle de l'espace social, structuré par des positions et des dispositions, où les agents se battent pour la possession d'un capital spécifique et qui a une autonomie relative dans la relation avec le pouvoir politique et économique.

Mots-clés: université, champ, champ universitaire, le néolibéralisme, l'enseignement supérieur.

Resumen Este artículo analiza el campo universitario portugués entre 1988 y 2015, con base en el discurso de 18 antiguos y actuales rectores y dirigentes estudiantiles y en los cambios sociales, económicos y políticos en este período. Primero, se describen aquellas que, según los agentes, constituyen las diez principales transformaciones de las instituciones universitarias. Después, se examinan los principales disensos suscitados de esas mismas transformaciones. Por último, a partir de estas transformaciones y disensos, analizamos la universidad como un campo, es decir, siendo un subconjunto relacional del espacio social, estructurado mediante posiciones y disposiciones, donde los agentes luchan por la posesión de un capital específico y que tiene una autonomía relativa en la relación con el poder político y económico.

Palavras-clave: universidad, campo, campo universitario, neoliberalismo, enseñanza superior 


\section{Introdução}

As universidades nas sociedades ocidentais têm pelo menos 928 anos de história. É nessa história, em particular nos séculos XIX e XX, que se estruturam as universidades modernas. Contudo, pese embora essa contextualização, que também abordaremos, este artigo centra-se nas transformações do campo universitário português entre 1988 e 2015, respondendo a três grandes questões. Quais foram as principais transformações no ensino superior português nos últimos 27 anos? O que nos revelam elas sobre as conceções em disputa entre os agentes? Podemos falar de um campo universitário com uma autonomia relativa no atual quadro do neoliberalismo e das mutações na organização do estado? ${ }^{1}$

Centrando na análise de entrevistas a atuais e antigos reitores e dirigentes estudantis, procurarei desenvolver três tipos de análise. Em primeiro lugar, irei explicitar as transformações que, segundo os agentes, são mais relevantes para perceber a transição da universidade portuguesa, discutindo-as no quadro das transformações económicas, sociais e políticas desde a segunda metade do século XX. Em segundo lugar, analisarei os principais dissensos que se identificam nos discursos dos agentes em torno das transformações do campo universitário. Finalmente, discutirei como estas transformações e disputas nos ajudam a refletir sobre as características de um campo universitário português, enquanto campo social com autonomia relativa no espaço social.

\section{Fronteiras de um programa de pesquisa: objeto, amostra e estratégia metodológica}

A definição desta pesquisa partiu do pressuposto defendido por Bourdieu, Chamboredon e Passeron (2010), de que não são neutras nem as escolhas metodológicas, nem a nossa própria posição no espaço social. Na verdade, o campo aqui em análise insere-se numa estrutura social marcadamente conflitual, na medida em que as transformações do ensino superior não têm ocorrido sem arrastarem consigo diversos dissensos. Por isso, a estratégia metodológica aqui usada procurou ampliar a nossa visão da diversidade do campo universitário e dos seus agentes, partindo da teoria como função de comando (Almeida e Pinto, 1975).

O objeto de estudo deste artigo não é, em estrito senso, as mudanças legislativas ou as mutações na organização universitária, nem é também uma historiografia dos percursos de resistência e/ou de consentimento às políticas educativas. O objeto que nos concentra é parte disso mas com uma perspetiva distinta. Parto do enquadramento histórico (Rubião, 2013; Dréze e Debele, 1983; Neto, 1999), da legislação (Amaral, Tavares e Santos, 2012; Magalhães e Amaral, 2007; Amaral, 2003; Barrias, 2013), das transformações organizacionais (Oliveira, Peixoto e Silva, 2014;

1 As reflexões a que este texto dá corpo têm origem numa pesquisa desenvolvida entre setembro de 2014 e junho de 2015 sobre as transformações e disputas nas universidades portuguesas entre 1988 e 2015. 
Quadro 1 Características da amostra referente a antigos e atuais reitores de universidades públicas

\begin{tabular}{|c|c|c|}
\hline \multicolumn{3}{|r|}{ Reitores } \\
\hline Nome & Universidade & Funções \\
\hline Virgílio Meira Soares & UL & $\begin{array}{c}\text { Reitor entre } 1986 \text { e } 1998 \\
\text { Secretário de estado do Ensino Superior em } 1985\end{array}$ \\
\hline José Barata-Moura & UL & Reitor entre 1998 e 2006 \\
\hline António Sampaio da Nóvoa & UL & Reitor entre 1999 e 2006 \\
\hline António Bensabat Rendas & UNL & $\begin{array}{l}\text { Reitor desde janeiro de } 2007 \\
\text { Presidente do Conselho de Reitores entre } 2010 \text { e } 2014\end{array}$ \\
\hline Manuel Santos Silva & UBI & Reitor entre 1996 e 2009 \\
\hline João Queiroz & UBI & $\begin{array}{l}\text { Reitor entre } 2009 \text { e } 2013 \\
\text { Diretor-Geral do Ensino Superior }\end{array}$ \\
\hline António Branco & UAlg & Reitor desde dezembro de 2013 \\
\hline Júlio Pedrosa & UA & $\begin{array}{c}\text { Reitor entre } 1994 \text { e } 2001 \\
\text { Presidente do CRUP entre } 1998 \text { e } 2001 \\
\text { Ministro da Educação do XIV Governo Constitucional de } \\
\text { Portugal }\end{array}$ \\
\hline
\end{tabular}

Quadro 2 Características da amostra referente a antigos e atuais dirigentes estudantis de associações de estudantes de universidades públicas

\begin{tabular}{ccc}
\hline & \multicolumn{2}{c}{ Dirigentes estudantis } \\
\hline Nome & Universidade & Funções \\
\hline Sandra Monteiro & UNL & Dirigente da AEFCSH-UNL entre 1988 e 1992 \\
\hline João Carlos Louçã & UNL & Dirigente da AEFCSH-UNL entre 1993 e 1997 \\
\hline Nuno Bio & UL & Dirigente da AEFCUL entre 1990 e 1995 \\
\hline Carlos Guedes & UL & Dirigente da AEFLUL entre 1992 e 1998 \\
\hline Pedro Sereno & UL & Presidente da Direção da AEIST \\
\hline Pedro Barrias & UP & Dirigente da AEFDUP entre 2001 e 2004 \\
\hline Nuno Fonseca & UC & Presidente da FAP entre 2006 e 2007 \\
\hline Eduardo Melo & UC & Membro da DG-AAC de 1992 a 1994 \\
\hline André Pereira & Dirigente da AAC entre 2007 e 2012 \\
\hline Gustavo Cardoso & Presidente da DG-AAC em 2011/2012 \\
\hline
\end{tabular}


Barrias, 2013) e das práticas políticas (Santos e Filho, 2008; Drago, 2005; Cabrito e Jacob, 2011) para desenvolver um quadro interpretativo da universidade enquanto campo, isto é, enquanto subconjunto relacional do espaço social, estruturado através de posições e disposições, onde os agentes lutam pela posse e o reconhecimento de um ou mais capitais, e que, tendo características próprias e uma autonomia relativa, funciona como um terreno de jogo, que se interseta com campos distintos, e onde os agentes disputam posições, significados e poder (Bourdieu, 1984a; 1984b; 1989; 1992; 2001; 2011).

Concentramo-nos no caso das universidades públicas ${ }^{2}$ e nos seus dois maiores corpos: professores e estudantes. Mas, procurando uma análise em torno do poder, analisarei os discursos de uma parte específica destes corpos: reitores e dirigentes estudantis. Do ponto de vista espaçotemporal centramo-nos nos últimos 27 anos, isto é, entre 1988 e 2015, e em oito universidades públicas, nomeadamente: Universidade de Lisboa (UL), Universidade Nova de Lisboa (UNL), Instituto Universitário de Lisboa (ISCTE-IUL), Universidade de Coimbra (UC), Universidade do Porto (UP), Universidade da Beira Interior (UBI), Universidade de Aveiro (UA) e Universidade do Algarve (UAlg).

A amostra mobilizada foi de 18 entrevistados, entre os quais oito atuais ou antigos reitores e dez atuais ou antigos dirigentes estudantis. Esta amostra procurou refletir quatro critérios: (a) a diversidade de universidades públicas em termos de dimensão e de localização; (b) a amplitude do ciclo temporal em estudo; (c) a representação da diversidade de protagonistas com responsabilidades universitárias no período em análise; e (d) o critério da diversidade de pontos de vista políticos sobre as principais transformações em análise.

\section{O campo universitário português no contexto internacional}

As transformações no ensino superior que aqui se identificam ocorreram num contexto histórico marcado por grandes mutações económicas e políticas. De facto, as políticas de educação superior enquadram-se nas tendências de definição das políticas públicas e da própria visão sobre o papel do estado. No nosso caso, foi na viragem da metade do século XX que à luz da relação de forças entre capital e trabalho, se expandiram as valências do estado social, no qual as políticas de democratização da educação foram um eixo central. Os acordos de Bretton Woods de 1944, não definindo a democratização da educação, simbolizaram a viragem política que a permitiu.

Contudo, o ciclo do pós-guerra foi interrompido logo nos anos 70 em consequência da crise do petróleo de 1973, do crash bolsista e da nova recessão de 1973-1975. A perda de hegemonia da escola keynesiana e o fim dos acordos de Bretton Woods mudaram o ciclo político, referindo Rui Canário (2005) que na

2 Importa referir que o sistema de ensino superior português se divide nos subsistemas universitário e politécnico. Por razões de espaço e tempo, optamos por analisar exclusivamente o caso do sistema universitário, tendo ainda assim consciência de que a análise do sistema de ensino superior politécnico tem uma enorme relevância na sociedade portuguesa. 
Quadro 3 Percentagem de alunos por natureza do sistema de ensino superior entre 1960 e 2013

\begin{tabular}{|c|c|c|c|c|c|c|c|c|c|c|}
\hline $\begin{array}{l}\text { Anos letivos/ } \\
\text { alunos }\end{array}$ & $1960 / 61$ & $1970 / 71$ & $1980 / 81$ & $1990 / 91$ & $2000 / 01$ & $2009 / 10$ & $2010 / 11$ & $2011 / 12$ & $2012 / 13$ & $2013 / 14$ \\
\hline $\begin{array}{l}\text { Ensino } \\
\text { superior } \\
\text { público }\end{array}$ & 90,8 & 93,4 & 90,5 & 72,1 & 70,3 & 75,7 & 77,7 & 79,8 & 81,7 & 83,3 \\
\hline $\begin{array}{l}\text { Ensino } \\
\text { superior } \\
\text { privado }\end{array}$ & 9,2 & 6,6 & 9,5 & 27,5 & 27,5 & 24,3 & 22,3 & 20,2 & 18,3 & 16,7 \\
\hline Total & 100,0 & 100,0 & 100,0 & 100,0 & 100,0 & 100,0 & 100,0 & 100,0 & 100,0 & 100,0 \\
\hline
\end{tabular}

Fonte: Ministério da Educação — Departamento de Ensino Superior, citado em Cabrito (2011) até 2011/2012; DGGEC para os anos 2012/13 e 2013/14.

Quadro 4 Percentagem do orçamento das instituições do ensino superior pelo Orçamento de Estado e receitas próprias entre 1990 e 2008

\begin{tabular}{lccccc}
\hline & 1990 & 1993 & 2000 & 2005 & 2008 \\
\hline Orçamento de Estado & 95 & 92 & 72,5 & 68,1 & 62,1 \\
\hline Receitas próprias & 5 & 8 & 27,5 & 31,9 & 37,9 \\
\hline Total & 100 & 100 & 100,0 & 100,0 & 100,0 \\
\hline
\end{tabular}

Fonte: DGEEC/MCES e OCDE, citados por Cabrito (2011).

educação se passou do "tempo de promessas", para um "tempo de incerteza". ${ }^{3}$ É nesse contexto que se desenha um novo paradigma com a eleição de Tatcher (1979) e Regan (1981) e com o estabelecimento do "Consenso de Washington" em 1989, onde instituições como o Fundo Monetário Internacional (FMI) ou o Banco Mundial (BM) passam a ter a função de consolidar o processo de neoliberalização que visou a redução da despesa pública, as privatizações e a desregulação.

No caso do BM, a promoção destas reformas refletiu-se de forma clara no ensino superior. Se fizermos uma análise diacrónica, identificamos um conjunto de recomendações relacionadas com: (a) a priorização do investimento na educação básica, propondo-se o cofinanciamento do sistema de ensino superior; ${ }^{4}(\mathrm{~b})$ a adaptação do sistema às lógicas da economia, através da privatização e de formas

3 É precisamente nessa década, em 1974, que Hayek publica O Caminho da Servidão (2010), onde defende que as soluções de tipo coletivista conduzem à violência e à supressão da liberdade, reforçando as ideias defendidas em 1962 por Milton Friedman (2014), que opondo-se ao welfare state, argumentava que a educação superior não devia depender sobretudo da iniciativa privada.

4 Estas e outras recomendações podem ser encontradas no relatório "Financing education in developing countries - an exploration of policy options" (1986). 


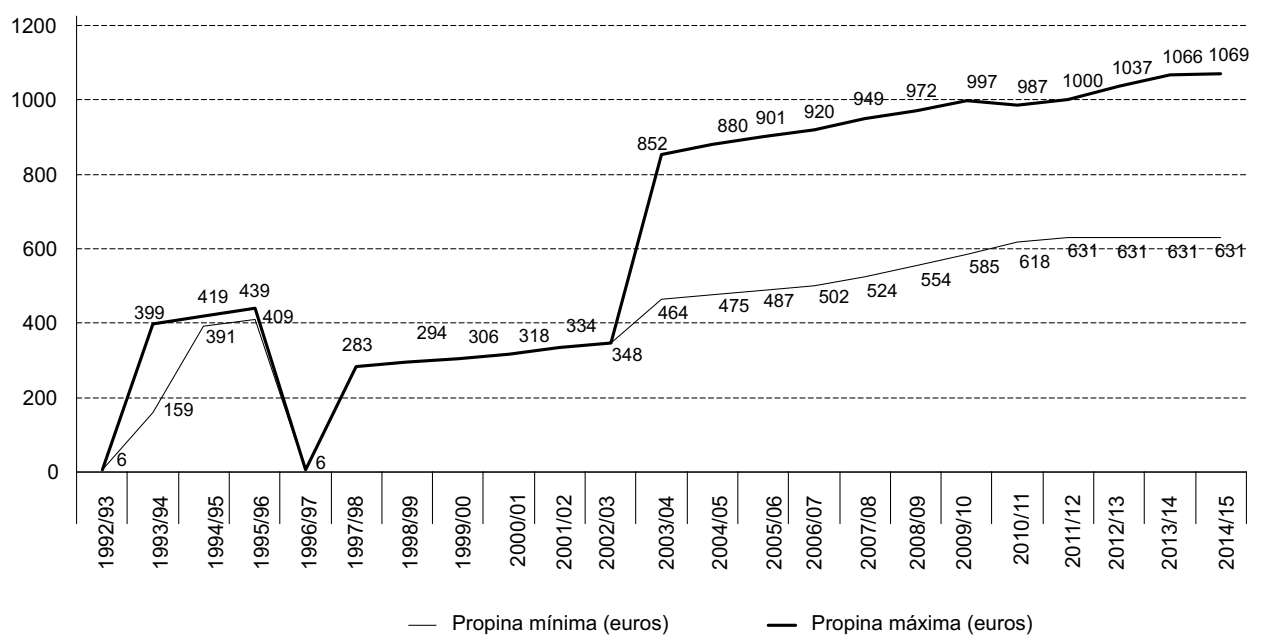

Figura 1 Evolução do valor da propina máxima e mínima em euros entre os anos letivos de 1992/93 e $2014 / 15$ no ensino superior público (a preços correntes)

Fonte: Cerdeira (2008) até ao ano letivo de 2007/08; recolha dos websites das IES para os valores entre 2007/08 e 2014/15.

alternativas de financiamento; ${ }^{5}$ (c) a submissão às leis do mercado, uma vez que a educação superior é sobretudo um "bem privado"; ${ }^{6}(\mathrm{~d})$ a aproximação das formações do mercado, dotando os estudantes de competências "empreendedoras" e "flexíveis"; ${ }^{7}$ (e) a substituição do termo "educação superior" por "educação terciária". ${ }^{8}$ É no contexto dessas orientações que o sociólogo e consultor do BM Michael Gibbons vem justamente defender o que designa o economically-oriented paradigm, no qual a universidade devia, em primeiro lugar, servir a economia, advogando que a sua relevância seria definida pela sua contribuição em termos de "performance económica" (Gibbons, 1998).

No caso português, só a partir do 25 de Abril de 1974 a democratização do ensino ganha tradução política e, desde esse momento, a expansão da oferta ocorreu a um ritmo acelerado. ${ }^{9}$ Mas a dinâmica de alargamento do sistema não foi isenta de contradições. Dados do Ministério da Educação, citados por Belmiro Cabrito

5 Estas e outras recomendações podem ser encontradas no relatório "Higher education: the lessons of experience" (1994).

6 Estas e outras recomendações podem ser encontradas no relatório "The financing and management of higher education: a status report on worldwide reforms" (1998).

7 Estas e outras recomendações podem ser encontradas no relatório "Higher education in developing countries: peril and promise" (2000).

8 Estas e outras recomendações podem ser encontradas no relatório "Constructing knowledge societies: new challenges for tertiary education" (2003).

9 A este respeito veja-se que, segundo dados do INE, em 1960 tínhamos apenas 0,9\% da população residente com o ensino superior, enquanto em 2013 essa percentagem já estava nos $15 \%$. 
(2011), mostram por exemplo que a oferta pública foi desde os anos 80 insuficiente para acompanhar a vontade crescente de acesso ao sistema. Em sentido oposto expandiu-se a oferta privada.

Os resultados são claros. Por um lado, assistimos a uma expansão da oferta privada como forma de absorver o número de jovens que procuraram este nível de ensino. Por outro, foi clara uma redução progressiva da verba do estado para as instituições, acompanhada pelo recurso a receitas próprias, principalmente através das propinas que, como se demonstra, e se explicará adiante, aumentaram a um ritmo acelerado nos últimos 23 anos.

\section{O ciclo 1988-2015 do campo universitário português: dez transformações estruturais destacadas pelos agentes universitários}

Nos discursos dos agentes universitários são identificadas dez transformações fundamentais nas universidades portuguesas.

Em primeiro lugar, a Lei da Autonomia Universitária de 1988. ${ }^{10}$ Esta consagrou o princípio da autonomia universitária, nomeadamente em termos estatutários, científicos, pedagógicos, administrativos e financeiros. Mas veio garantir também a gestão democrática assente em quatro órgãos: a Assembleia da Universidade, onde tinha de haver "paridade entre os docentes e os estudantes eleitos", 11 que aprovava estatutos e elegia o reitor; o reitor, eleito por escrutínio secreto, cabendo-lhe propor as linhas gerais da universidade, representá-la ou superintender a gestão; o Senado Universitário, constituído por docentes e estudantes, respeitando a paridade, e também por funcionários, ${ }^{12}$ competindo-lhe aprovar as grandes linhas de orientação, atividades, organização interna, bem como exercer poder disciplinar ou fixar propinas; e o Conselho Administrativo, órgão colegial do qual fazia parte o reitor, um vice-reitor, o administrador e um representante dos estudantes.

Em segundo lugar, o aumento das propinas. No início dos anos 90 pagava-se uma taxa que hoje seria de cerca de 6 euros. O aumento, que se discutia desde o início da década, ${ }_{13}^{13}$ confirma-se com a Lei n. $.20 / 92$, provocando um aumento para o que hoje seriam 399 euros na propina máxima e 159 na mínima. Apesar da contestação acontecer desde 1990, é esse aumento de 1992 que a amplia, com mobilizações de rua e bloqueios de órgãos de gestão. Depois de três ministros tentarem sem sucesso

10 Lei n. ${ }^{\circ}$ 108/88, de 24 de setembro.

11 Dela faziam também parte o reitor, os vice-reitores, presidentes dos órgãos de gestão das unidades orgânicas, presidentes das associações de estudantes, o administrador e o vice-presidente dos serviços sociais (artigo $17 .^{\circ}$ ).

12 Não sendo obrigatório, a lei permitia ainda integrar representantes externos à universidades, em número não superior a $15 \%$ da totalidade dos seus membros.

13 Apesar de as propinas para as licenciaturas só sofrerem um aumento com a lei de 1992, este já tinha sido proposto em 1990 no Livro Branco sobre o Financiamento Público ao Sistema de Ensino Superior, da autoria de Afonso de Barros, Daniel Bessa e outros. 
implementar a lei, ${ }^{14}$ esta é suspensa em 1995. Mas a suspensão durou pouco tempo. Depois de dois anos, o XIII Governo Constitucional, chefiado por António Guterres, aprova a Lei n. ${ }^{\circ} 113 / 97$, onde se fixa a propina no valor do salário mínimo. Essa lei havia de durar até à aprovação da Lei n.o 37/2003, em que se verificou um grande aumento, com a fixação de um valor mínimo de 1,3 vezes o salário mínimo nacional e um valor máximo que passa a ser o referente ao valor de 1941, indexado à inflação. Esta alteração fez as propinas aumentarem de 348 euros em 2002, para 464 euros de propina mínima e 852 euros de máxima em 2013. Assim, progressivamente, a introdução da ideia da "partilha de custos" (Cerdeira, 2009; 2008), ocorreu em paralelo com a "descapitalização pública" das universidades (Santos e Filho, 2008).

Em terceiro lugar, destacam-se as mudanças ao nível do financiamento público. Por um lado, é referida pelos agentes a criação de uma fórmula de financiamento em $1993 .{ }^{15}$ Por outro lado, é dado relevo aos cortes no financiamento público que se encontram na ordem dos $30 \%$ desde $2010 .{ }^{16}$

Em quarto lugar, salienta-se a adesão ao Processo de Bolonha em 1999.17 Este promoveu a constituição de um Espaço Europeu de Ensino Superior, assente em cinco objetivos: (a) a adoção de um sistema baseado em duas fases, a pré-licenciatura de duração mínima de três anos e a pós-licenciatura que deveria conduzir aos graus de mestre e doutor; (b) a criação de um sistema de créditos; (c) o incentivo à mobilidade para estudantes, professores, investigadores e pessoal administrativo; (d) a cooperação europeia nos processos de garantia da qualidade; (e) a promoção de dimensões europeias ao nível do desenvolvimento curricular, programas de estudo, estágio e investigação. Como se perceberá, os impactos de Bolonha estão longe de ser consensuais.

Em quinto, a introdução do Regime Jurídico das Instituições de Ensino Superior (RJIES) em 2007,18 que redefine a estrutura de gestão das universidades criada com a Lei da Autonomia Universitária de 1988. Uma das principais mudanças foi a introdução do Conselho Geral, um órgão com 15 a 35 membros, dos quais o corpo de professores deve constituir mais de metade do conselho e os estudantes representarem um mínimo de $15 \%$, e onde se introduz a presença de membros externos com uma presença de no mínimo $30 \% .{ }^{19}$ Este órgão acaba com a paridade de estudantes e professores e introduz elementos externos. Ele incorpora as funções antes atribuídas à Assembleia da Universidade e ao Senado, e uma das suas implicações teve a ver

14 Respetivamente, Diamantino Durão (1991-1992), Couto dos Santos (1992-1993) e Manuela Ferreira Leite (1993-1995).

15 Esta fórmula durou até 2009. Em 2010 e 2011 o financiamento foi baseado na fórmula de 2009 complementado com financiamento atribuído por contratualização de objetivos, o Contrato de Confiança. No ano de 2013, o financiamento voltou a ser feito com base numa fórmula, que tem em consideração o histórico do orçamento anterior (85\%) e a reposição da fórmula usada até 2009 (15\%).

16 Estes cortes fizeram com que em muitas universidades hoje o financiamento público já não chegue aos $50 \%$ do seu orçamento.

17 A Declaração de Bolonha, assinada a 19 de junho de 1999, encontra-se disponível em: http://www.magna-charta.org/resources/files/BOLOGNA_DECLARATION.pdf

18 Lei $n .{ }^{\circ}$ 62/2007, de 10 de setembro.

19 Não sendo obrigatório, a estes membros podem ainda juntar-se representantes dos funcionários não docentes. 
com a mudança no método de eleição do reitor, que deixou de ser eleito através de um colégio eleitoral, para ser eleito pelo Conselho Geral, de número mais reduzido e do qual fazem parte membros externos. O RJIES introduz ainda a possibilidade de as instituições se candidatarem ao regime fundacional, que lhes permite ter uma gestão em regime de direito privado e um novo órgão máximo, o Conselho de Curadores, constituído exclusivamente por membros externos cooptados, "de elevado mérito e experiência profissional reconhecidos como especialmente relevantes".

Um sexto aspeto está relacionado com a incorporação da missão científica nas universidades. Esta mudança implicou um aumento da qualificação nos graus mais elevados, novas carreiras e mais investigação científica nas universidades.

Em sétimo lugar, salientam-se as questões do acesso e do abandono escolar. Por um lado, é destacada uma crescente redução de candidatos ao ensino superior nos últimos anos. De facto, segundo dados da Direção-Geral de Estatísticas da Educação e Ciência, entre 2011 e 2014 o número de matriculados pela primeira vez no público caiu de 102.895 para 87.381 estudantes. ${ }^{20} \mathrm{E}$ por outro lado, é destacado o crescente número de estudantes que abandonam os estudos e que, segundo o Ministério da Educação, só entre 2012 e 2013, foram cerca de 9 mil.

Em oitavo lugar, destacam-se as questões relativas ao corpo docente. Por um lado, é salientado o seu envelhecimento. Por outro, é destacada a qualificação deste corpo, em particular ao nível do doutoramento.

Em nono lugar, as mudanças na Ação Social Escolar. É relevado por antigos dirigentes estudantis que, já no início dos anos 90 , o reforço da ação social era apresentado como contrapartida para o aumento das propinas. Essa perspetiva continua presente para os atuais dirigentes. Mais recentemente, as questões da ação social são mencionadas relativamente aos cortes do Decreto-Lei n.. $70 / 2010$ às bolsas de estudo ${ }^{21}$ ou à introdução das dívidas fiscais e contributivas da família como critério de exclusão do acesso à bolsa. A estas alterações correspondeu um ciclo de contestação estudantil que forçou o recuo por parte do poder político.

Finalmente, salientam-se nas entrevistas as mudanças nos processos de avaliação e acreditação, feitos desde 2007 pela Agência de Avaliação e Acreditação do Ensino Superior (A3ES), que mudou as regras e os métodos de avaliação e acreditação, deixando esta de ser feita entre pares, para passar a ser tutelada por uma agência externa pública de direito privado cujos critérios são reconhecidos por outras agências europeias e pela European Universities Association.

\section{Um campo em disputa: dissensos, polémicas e controvérsias de um campo em transformação acelerada}

As dez transformações que sintetizei estão longe de ter sido consensuais entre os agentes universitários. O seu desenho foi sempre influenciado pela dinâmica

20 Se virmos o número de matriculados no ensino público, ele reduziu-se de 311.547 em 2012 para 301.654 estudantes em 2014. Quase menos 10 mil inscritos matriculados em dois anos.

21 Decreto-Lei n. ${ }^{\circ}$ 70/2010, de 19 de julho. 
conflitual que originaram ou que as antecederam no campo universitário. Vejamos os 11 principais dissensos identificados nos discursos dos agentes.

\section{Bolonha: entre a formação geral e as competências para o mercado de trabalho}

O Processo de Bolonha introduziu enormes transformações na organização da formação. Júlio Pedrosa, antigo reitor da UA, destaca que "na Declaração de Bolonha aparece claramente um primeiro grau com um grande potencial de inserção no mercado de trabalho". Mas a visão de que o $1 .{ }^{\circ}$ ciclo deve ter o objetivo de ingresso profissional está longe de ser consensual, na medida em que vários agentes referem que $\mathrm{o}$ modelo que veem para o futuro de Bolonha é o do reforço das formações gerais no 1. - ciclo, transformando o 2. . ciclo numa formação de vocação mais profissional ou de investigação.

Esta polémica não é nova. Em 1807, na fundação da Universidade de Berlim, Humboldt desenhou um modelo baseado na liberdade e autonomia académica e numa conceção da "formação pelo saber" - Bildung durch Wissenschaft -, através da unidade ensino/pesquisa, na qual a formação daria grandes bases de pesquisa científica fundamental (Humboldt, 1997). Por sua vez, na tradição inglesa da "educação liberal", John Newman (1996) defendeu que as funções da profissionalização e da pesquisa deviam ser precedidas de uma formação geral capaz de desenvolver o raciocínio e o espírito público. É desses debates que, com a criação da Johns Hopkins University, em 1875, se constrói um modelo de formação geral assente em quatros anos - os colleges - e um segundo nível de formação especializada - as graduate schools. Como se percebe, sendo esta uma questão antiga, ela está longe de estar encerrada no campo universitário português.

O tempo da formação: três mais dois (não) é igual a cinco?

Outro objeto de discordâncias relativamente a Bolonha foi a redução do número de anos de cada ciclo. Se, para António Rendas, reitor da UNL, a questão deve ser centrada na importância da qualificação ao longo da vida, outros como José Barata-Moura, antigo reitor da UL, afirmam que a redução das formações "é um disparate monumental, porque [...] na formação das pessoas, há uma variável fundamental que é a variável tempo". Já para Manuel Santos Silva, antigo reitor da UBI, "[Bolonha] foi uma forma de desqualificarmos os jovens em alguns aspetos $[\ldots]$ porque três mais dois, não é igual a cinco $[\ldots]^{\prime \prime}$.

Propinas: 23 anos de polémica

O aumento das propinas desde 1992, acompanhado nos últimos anos com o que Boaventura de Sousa Santos (Santos e Filho, 2008) designa descapitalização pública da universidade, conduziu a posicionamentos muito distintos. No quadro das entrevistas, identificamos três posições em confronto. A primeira refere-se àqueles que são explicitamente contra a fixação das propinas, na medida em que a justiça social se deve fazer por via fiscal e em que constitui um dever do estado proporcionar a tendencial 
gratuitidade do ensino superior. A segunda refere-se aos que afirmam que não há alternativa, quer pelo peso que as propinas têm no orçamento das instituições, quer por razões estratégicas de exigência de mais financiamento público. A terceira posição reflete-se em quem concorda com o princípio das propinas pelas vantagens individuais que os diplomados têm no mercado ${ }^{22}$ ou porque elas devem servir para a melhoria da qualidade ou da ação social.

\section{Colegialidade e dimensão dos órgãos de gestão}

Uma dimensão fundamental da transformação do campo universitário teve que ver com a mudança nos órgãos de gestão. Vários reitores argumentam que a redução dos membros do Conselho Geral, em relação aos principais órgãos, estabelecidos em 1988, não introduz um caráter menos democrático uma vez que as universidades podem criar outros métodos de auscultação. Outros destacam o facto de a dimensão excessiva dos antigos órgãos criar desresponsabilização. Contudo, vários agentes referem que o RJIES "é um sistema claramente menos democrático" porque faz com que os corpos participem cada vez menos na vida interna da universidade. Hoje as posições confrontam-se entre a necessidade de eficiência dos órgãos e a exigência da participação interna em órgãos democráticos e representativos.

\section{Que representação dos corpos internos e externos?}

Uma das transformações mais importantes no que respeita aos órgãos de gestão foi o fim da paridade entre docentes e estudantes. Mas esse não foi o único fator de dissenso. Outro teve a ver com a introdução de membros externos. Para Júlio Pedrosa, antigo reitor da UA, é "trazerem para dentro vozes de fora, o que é boa notícia, porque as universidades são entidades públicas", mas outros agentes universitários defendem um modelo alternativo em que os membros externos estariam numa estrutura consultiva da instituição, e não nos seus órgãos deliberativos.

\section{Que tipo de abertura à sociedade?}

A questão da presença de membros externos não se coloca apenas no tipo de representação que estes devem ter, mas também sobre as implicações da sua presença. De facto, os agentes universitários chamam a atenção para as possíveis consequências da presença do setor privado nos órgãos de gestão, da cópia dos seus procedimentos e metodologias, e para a necessidade de preservação da autonomia científica nesse contexto. Sendo a relação da universidade com os outros campos do poder, nomeadamente o político e o económico, uma polémica longa, estas preocupações estão longe de estar encerradas.

22 A legitimação das propinas em nome dos benefícios que os diplomados têm no mercado de trabalho também foi identificada, no caso do Reino Unido, por Boden e Nedeva (2009). 
A democraticidade na eleição do reitor

Passando da Assembleia da Universidade para o Conselho Geral, o método de eleição do reitor mudou radicalmente, na medida em que, em vez de a eleição ser feita através de um colégio eleitoral amplo, passou a ser feita por um órgão com menos representatividade, onde participam membros externos à universidade, cooptados, e que acumula as funções de desenvolvimento estratégico e supervisão das instituições. Essa mudança não foi, nem é, pacífica. Enquanto antigos reitores a classificam como um "retrocesso" ou uma importação de "culturas que não temos", outros referem que o modelo é melhor "principalmente pela presença dos elementos externos dentro da universidade".

\section{Educação e mercado de trabalho: para que serve a empregabilidade?}

Como defendi noutra ocasião (Mineiro, 2015), a mais recente literatura sobre a noção de "empregabilidade" mostra como ela adquiriu um uso ideológico muito forte, relacionado com o tipo de formação que os diplomados supostamente devem ter para estarem "empregáveis". Mas para além do debate sobre as "competências de empregabilidade" nos currículos, uma das questões muito presentes é a definição das vagas de cada instituição em função dos "índices de empregabilidade". As opiniões dividem-se entre os que acham que o sistema deve ser regulado tendo em conta estes indicadores e aqueles que consideram que este não é um fator crucial a ter em conta.

O regime fundacional: entre a natureza pública e o direito privado

Uma outra disputa entre os agentes no quadro da implementação do RJIES teve que ver com a introdução do regime fundacional. Se para uns agentes este regime "reforça as lideranças", permite "uma maior responsabilidade de quem dirige"e garante universidades mais "ágeis" e "flexíveis", para outros ele "parece ser claramente uma porta aberta para dinâmicas de privatização". Na verdade, o modelo fundacional mantém dimensões de natureza pública (como sejam as regras da fixação de propinas ou de vagas), mas introduz mecanismos de gestão privada que estão longe de ser consensuais entre as universidades públicas.

\section{A ideia da "universidade de excelência"}

O conceito de excelência é dos mais marcadamente polissémicos, mas também dos mais usados na apresentação das instituições. Para alguns agentes a universidade de excelência é a que consegue atingir os patamares de empregabilidade, eficiência formativa e investigação, e ter "capacidade de se gerir por si própria"; para outros ele é um conceito "vazio" ou "chavão", relacionado com a mercantilização das universidades. 


\section{A questão da avaliação e acreditação das instituições}

Importa ainda assinalar algumas discordâncias sobre as questões da avaliação e acreditação. Alguns agentes destacam que com as mudanças recentes as universidades perderam autonomia pedagógica, enquanto outros preferem salientar que $o$ papel da agência A3ES tem contribuído para consolidar a qualidade dos cursos. Contudo, há ainda quem argumente que este modelo "é uma vergonha" porque se baseia num sistema de "prémios e castigos" quebrando as experiências anteriores.

\section{Podemos falar de um campo universitário?}

Como tentei demonstrar, as universidades não são imunes às dinâmicas sociais, económicas e políticas do tempo histórico em que se inserem. Contudo, elas são também motores de transformação e mudança social. O que é que as transformações e disputas destes 27 anos, nos podem revelar sobre o lugar da universidade nas dinâmicas da sociedade contemporânea?

\section{Universidade enquanto campo?}

No período aqui em análise, as universidades transformaram-se profundamente, principalmente ao nível do financiamento, da organização interna e da relação com o exterior. Nesse contexto, podemos falar da universidade enquanto campo social, isto é, enquanto subconjunto relacional do espaço social, dotado de autonomia relativa, caracterizado pela disputa de um capital, e cuja existência é irredutível a outros campos?

Gostava de propor uma hipótese pluralista para essa questão. Apesar de uma clara pressão economicista e mercantil, a universidade persiste enquanto subconjunto do espaço social passível de ser entendido enquanto um campo. É na sua dinâmica que se pode entender não apenas a posição dos agentes em disputa por um conjunto particular de capitais, mas também as suas lutas pelo reconhecimento do campo na relação com o estado e o mercado. É por constituírem um campo que as universidades ainda não são hoje uma mera expressão do mercado ou da administração pública. São sobretudo um palco de avanços e recuos, consentimentos e resistências, competição e solidariedade, em torno dos processos de transformação que se foram e vão sucedendo à escala internacional, mas que têm em Portugal uma configuração específica.

Acesso, doxa e um certo "sentido do jogo"

O direito de acesso a um campo é atribuído pelo reconhecimento dos seus valores e regras fundamentais - daquilo que (e como) nele se joga -, e do tipo de capital que nele se disputa. Apesar da diversidade de dissensos, é muito clara a forma como os agentes reconhecem um conjunto de valores comuns associados à pertença ao campo universitário. Entre eles, a importância da qualificação, o contributo 
para o desenvolvimento económico e social, a promoção da cidadania e do espírito crítico, a inserção profissional vantajosa ou a promoção do desenvolvimento científico e tecnológico.

Mas a admissão no campo, para além da adesão a um conjunto de pressupostos valorativos, implica igualmente a posse de diferentes capitais que legitimam a entrada. Desde logo de capital económico, na medida em que pertencer ao campo implica o cofinanciamento dos custos da educação, ${ }^{23}$ e de capital cultural, na medida em que a entrada depende da anterior acumulação de capital cultural certificado pelo estado. ${ }^{24}$ Mas pode ainda implicar a posse de capital simbólico, na medida em que o acesso implica um reconhecimento que distingue a posse dos meios económicos e culturais de quem acede, e de capital social, uma vez que se podem ativar redes facilitadoras de acesso. ${ }^{25}$ Assim, a mobilização de diferentes capitais é um fator explicativo do conjunto de disposições, de um habitus ou de uma hexis (Bourdieu, 2011) que orienta os agentes para a importância da presença no campo. ${ }^{26}$

São essas faculdades de acesso e essas disposições incorporadas que constituem a doxa (Bourdieu, 1984a) do campo universitário: a adesão a um entendimento tácito, entre efetivos e potenciais agentes, de um conjunto de leis e regras que regulam o acesso, a pertença e a luta, bem como dos benefícios individuais e coletivos da participação no campo. Dessa doxa faz parte precisamente o que Bourdieu (2001) chama "sentido do jogo", isto é, um certo senso prático que faz com que os agentes, ao jogarem, respondam às exigências das regras do campo, aceitando as regras inerentes à disputa da posse de um conjuntos de capitais transponíveis para o conjunto do espaço social. ${ }^{27}$

\section{Capitais em disputa: uma aproximação à ideia de capital universitário enquanto capital compósito}

Uma questão central da definição de um campo é precisamente a de saber que capital nele se disputa e que posições se ocupam na luta pela sua dominação (Bourdieu,

23 Isso manifesta-se nos estudantes que querem aceder à universidade, mas também para professores que têm de concluir os vários graus de formação para ingressarem numa carreira docente.

24 Na verdade, é a avaliação quantitativa desse tipo de conhecimentos anterior à universidade as chamadas "médias" - , que regula a relação entre o número efetivo de candidatos à entrada e o número de vagas disponíveis. Quem está melhor avaliado nos graus antecedentes tem acesso prioritário ao campo.

25 Um exemplo paradigmático é a possibilidade da ativação de redes de contactos na universidade que facilitem candidatura a uma bolsa de estudo para suportar os custos da educação ou o simples processo de candidatura e entrada num curso.

26 Esse habitus do campo pode ser desenvolvido e instigado dentro e fora dele pelos seus próprios agentes internos (professores, estudantes, antigos estudantes, investigadores, reitorias, funcionários, etc., que produzem discursos sociais sobre a importância da pertença ao campo), mas também por agentes externos (estado, mercado, governo, sociedade civil, etc., que inscrevem narrativas na sociedade sobre as função do campo e as vantagens de lhe pertencer). 27 Delas fazem parte, para estudantes, a aceitação dos mecanismos de avaliação e classificação, re-
gras pedagógicas, custos da formação, currículos, hierarquias internas ou regras de acesso. Para professores, sistemas de avaliação de desempenho, regras laborais de progressão na carreira, estatutos docentes, regras salariais ou hierarquias internas. 
1984b; 2001). Se falar de um campo universitário é também falar de campos que nele se refletem, como os campos educacional, profissional, de pesquisa e cultural (Cunha, 2006), o que me leva a considerar a existência de um campo universitário analiticamente delimitado? Gostava de avançar na hipótese de que a universidade constitui um campo porque nela se disputa o capital universitário, isto é, um capital compósito que reflete a articulação dos quatro capitais propostos por Bourdieu na sua teoria geral dos campos, os capitais económico, cultural, social e simbólico.

Capital económico porque a presença no campo pode potenciar uma posição económica mais favorecida na sociedade. A mobilidade social inerente à pertença ao campo constitui um elemento definidor das lutas pelo acesso, pela permanência ou pela conclusão com sucesso da passagem pelo campo. ${ }^{28}$

Capital cultural porque algumas das justificações dadas pelos agentes para o acesso e a pertença ao campo são, por um lado, a possibilidade de exponenciar os conhecimentos que se tem do mundo e da sociedade e, por outro lado, a possibilidade de que esses conhecimentos se traduzam em qualificações e competências mobilizáveis fora do campo, por exemplo, na esfera profissional, na esfera pública ou nas práticas de cidadania.

Capital simbólico, porque a pertença ou a passagem pelo campo constituem em si mesmas um traço de distinção social. Revelador disso é o facto de a um tipo de formação corresponder um título formal de apresentação. Mas também a ideia de que o conhecimento nele produzido é um conhecimento distintivo em relação a outras formas de conhecimento na sociedade..$^{29}$

E finalmente o capital social, que pode potenciar a criação, ampliação e ativação das redes que facilitem a inserção no mercado de trabalho, a investigação científica, a presença no espaço público, ou que auxiliem a mobilidade nas hierarquias do mercado de trabalho.

O capital universitário é, por isso, um capital compósito distintivo, na medida em que pode ser mobilizado enquanto elemento potenciador de capital económico, cultural, simbólico e social. Por isso, é um capital flexível e adaptável à dinâmica das trajetórias sociais e estrategicamente transponível para o conjunto do espaço social.

\section{Podemos falar de "autonomia relativa"?}

Apesar de os campos só poderem ser interpretados na sua interdependência, uma das suas características centrais é a sua autonomia relativa, enquanto microcosmo social, com regras próprias, em disputa, e que são irredutíveis ao funcionamento de outros campos (Bourdieu, 1984b; 1992).

28 Entre outras, podemos ter como exemplo as lutas pela a redução de propinas ou a melhoria de bolsas (para facilitar o acesso), as estratégias contra o abandono (para assegurar a permanência), ou os mecanismos de promoção do sucesso escolar (para facilitar a conclusão da passagem pelo campo com sucesso).

29 Exemplo curioso desse facto é a expressão "fuga de cérebros", que tende a privilegiar na sociedade a preocupação com a emigração dos jovens qualificados, invisibilizando a emigração não qualificada. 
Se olharmos para as pressões economicistas, para a descapitalização pública e para as pressões de organizações nacionais e supranacionais externas à universidade que tentam influenciar as suas prioridades científicas, curriculares ou pedagógicas, podíamos tender para a hipótese do fim da "autonomia universitária". Mas essa hipótese seria demasiado redutora. Na verdade, a reação dos agentes à heteronomia tem feito com que a relação de forças esteja também em mutação e, por isso, as universidades ainda não sejam uma mera expressão de interesses empresariais ou políticos, mas sim um espaço de lutas e disputas, nos seus avanços e recuos, onde os próprios campos e agentes em confronto se vão redefinindo. Essa dinâmica é, provavelmente, a melhor expressão da autonomia relativa do campo.

Campo e interação: a universidade entre o estado e o mercado no quadro do new public management

Estando as universidades sob administração indireta do estado, as pressões economicistas e mercantis a que fiz referência, só podem ser entendidas no contexto das mutações do próprio estado com o new public management (NPM).

O NPM designa um conjunto de reformas surgidas no final dos anos 70 (Hood, 1991) que traduziram uma aproximação entre o setor público e o setor privado e uma crescente penetração dos valores de mercado na esfera pública. As mudanças introduzidas por estes novos métodos de gestão traduziram-se na organização das universidades, sintezando-se, segundo Barrias (2013), em nove princípios. Em primeiro lugar, o NPM introduziu um novo paradigma de aproximação ao mercado e à utilização de instrumentos de gestão privada. Em segundo, reforçou a autonomia institucional em relação ao estado. Em terceiro, centralizou as decisões mitigando a representatividade e colegialidade. Em quarto, profissionalizou a gestão. Em quinto, promoveu uma alteração dos mecanismos de financiamento através de fórmulas baseadas na "desconfiança sistémica". Em sexto, promoveu um conjunto de novos valores, como a prestação de contas, a produtividade ou a angariação de receitas. Em sétimo, estimulou a uma maior prestação de contas. Em oitavo, acentuou a promoção de novos "perfis de liderança" mais dedicados à gestão de finanças e recursos humanos. E, finalmente, alterou leis laborais com a promoção de políticas de recursos humanos privadas.

O conjunto destas mudanças transformou a interação do campo universitário com o mercado e o estado. A diluição dessas fronteiras manifesta-se em 12 características sociologicamente relevantes: (a) a atuação das instituições passou a basear-se na competição, operando em condições de quase-mercado; ${ }^{30}(\mathrm{~b})$ aprofundaram-se estruturas de lógica empresarial; (c) desenvolveu-se o caráter comercial na captação de estudantes e competição entre funcionários; (d) mitigou-se a representatividade e colegialidade dos órgãos, agora substituídos por lideranças centralizadas e novos órgãos com membros externos; (e) os reitores passaram a assumir funções de gestão semelhantes às do setor privado; (f) os órgãos de representação como o Senado

30 O termo quase-mercado designa contextos organizacionais em que, apesar de existir financiamento ou cofinanciamento por parte do estado, também estão presentes mecanismos de funcionamento de mercado (Bertolin, 2011). 
foram secundarizados; (g) encareceram-se os custos do ensino; (h) mercantilizou-se o campus; (i) apostou-se nas instituições enquanto marcas comerciais; (j) criaram-se novas parcerias com o capital privado para a obtenção de receita própria; (k) os estudantes passaram a ser entendidos como clientes; (1) o acesso à universidade deixou de ser entendido como um direito, por meio da cidadania, mas sim como um serviço, por meio do consumo.

A reconfiguração das universidades mostra-nos que a diluição das fronteiras entre o campo universitário e o campo económico se concretiza precisamente no quadro das transformações do próprio estado. Mas ao constituírem um campo social, as universidades não viram estas transformações ocorrer sem intensas disputas internas que, em muitos casos, continuam em aberto.

\section{Interação e disputa interna: um sentido das lutas no campo universitário}

No final dos anos 80, em La Noblesse d'Etat (1989) Bourdieu analisa a estrutura da educação francesa organizada entre as grandes écoles, de formação de elite, e as universidades, instituições de massas e que não estão necessariamente ligadas ao mundo do trabalho. Uma das dimensões da diferenciação é precisamente a dualização institucional que tende a mimetizar as desigualdades sociais no sistema de educação. Mas o que sobressai nesta pesquisa não é tanto uma disputa sobre a diferenciação interna no sistema universitário português, mas sobretudo sobre a relação que o campo universitário estabelece com os campos que o circundam.

Na verdade, as disputas dos agentes sobre algumas das matérias mais estruturantes do processo de mudança dos últimos 27 anos são reveladoras de disputas mais amplas sobre a natureza da autonomia do campo universitário, nomeadamente na sua relação com o estado, o mercado e a sociedade. Com o estado quando, por exemplo, no quadro da Lei da Autonomia Universitária, do RJIES ou dos novos processos de avaliação, se opõem conceções sobre o grau de autonomia que o poder político deve atribuir às instituições. Com o mercado quando, no quadro do aumento das propinas, das novas regras de gestão ou dos novos valores em emergência, se disputam posições sobre a maior ou menor necessidade de mimetismo com esfera privada. E com a sociedade, porque no conjunto das transformações que analisei se opõem visões distintas sobre o tipo de interação que a universidade deve estabelecer com a sociedade em que se inscreve. O desenho da autonomia do campo universitário, nomedamente na sua permeabilidade ao poder político e económico, parece ser uma das arenas em que os agentes mais disputam lutas pela dominação interna.

\section{A função social da universidade: aproximações e desencontros}

Um elemento central da definição do campo é a função que os agentes lhe atribuem. Analisando as respostas à questão "qual é a função social da universidade?", é possível encontrar elementos de convergência que refletem uma narrativa confluente, mas também elementos de divergência ou de destaque diferenciado.

No plano da opinião consensual, encontramos um conjunto amplo de justificações para a função social da universidade, como sejam as de colocar as pessoas a 
pensar contribuindo para a formação pessoal, promover o ensino e a qualificação, formar bons profissionais, estimular a investigação científica ou contribuir para o desenvolvimento económico, social e cultural.

Mas se estas funções constituem elementos relativamente consensuais, no concreto elas desdobram-se em funções destacadas de modo divergente pelos agentes. Enquanto uns falam da função de formar recursos humanos, outros de formar cidadãos livres. Uns destacam a promoção do pensamento culto, outros da formação técnica. Uns privilegiam a necessidade de garantir a aplicabilidade do conhecimento, outros de formar gente crítica. Uns de dar respostas a nível tecnológico, outros de se organizar para a autonomia. Uns a missão do direito à educação independentemente da origem económica ou regional, outros de contribuir para a competitividade económica. Uns destacam a promoção da justiça social, outros a função de contribuir para o crescimento dos estados. Uns acentuam a função de combater as desigualdades, outros de garantir os benefícios individuais da educação. Uns destacam a promoção da competitividade, outros a função de garantir uma experiência democrática e de participação cidadã. Uns a função de soberania, outros a de crescimento económico. Uns de promoção de uma sociedade coesa e solidária, outros de garantir a função de contribuir para o desenvolvimento económico local.

A maioria destas funções não são nem dicotómicas, nem mutuamente exclusivas. Elas provavelmente poderiam ser melhor agrupadas se estivéssemos a analisar a diferenciação entre universidades e politécnicos. Mas mesmo analisando apenas o campo universitário, o destaque dado pelos diversos agentes a cada função da universidade revela também a identificação de posições divergentes sobre a natureza e o futuro das universidades no século XXI. É a intensidade das disputas no campo que aqui analisámos e são as relações de força que nele se estruturam que colocam o seu futuro tão aberto e imprevisível nesta transição de século.

\section{Conclusão}

Em 2009, dizia George Steiner em Lisboa que “desde a sua instauração em Bolonha, Salerno ou Paris medieval, as universidades são bichos frágeis mas tenazes". Foi esse o caminho desta pesquisa: nele procurámos olhar para a tenacidade que faz das universidades uma das mais notáveis invenções da humanidade; mas olhámos também para a fragilidade da sua exposição às mais diversas formas de pressão política e económica, no quadro da intensificação do neoliberalismo e das transformações no estado.

É verdade que a pressão mercantil e as transformações do estado com a emergência do new pubic management são uma realidade que tem reflexos profundos no que são hoje as universidades portuguesas. Contudo, se analisarmos os discursos diretos dos agentes universitários dos 27 anos que aqui se escrutinam, somos levados à conclusão de que a universidade não tem sido um espaço amorfo e isento de conflitos. A sua primeira característica enquanto campo é precisamente o facto de as suas transformações nestes 27 anos não terem ocorrido sem disputas intensas no 
seu seio, condicionando avanços e recuos na relação da autonomia da universidade no conjunto do espaço social.

Estas transformações e disputas, sendo parte intrínseca e constitutiva do campo, mostram como tem mudado a relação da universidade com o estado e o mercado. Mas é precisamente pelo facto de a universidade constituir um campo social que ela não é hoje uma mera expressão de nenhum dos dois, mantendo características próprias e elementos de autonomia. Apesar da pressão economicista e mercantil, é a "autonomia relativa" que lhe permite constituir-se como um microcosmo social que, na sua dinâmica interna, redefine permanentemente, mediante a relação de forças de cada momento, a relação de interseção com as suas fronteiras.

Apesar dos elementos de autonomia, a colonização crescente do campo universitário pelo poder económico a partir do estado, tem colocado em causa alguns domínios da missão pública das universidades. Contudo, o que sobressai nesta pesquisa é que não há nenhum elemento que nos permita antecipar o resultado das disputas ou da configuração futura da relação de forças interna do campo. A essa tentação para cartomancia sociológica só podemos responder com uma certeza: a existir, o campo universitário continuará a reagir de forma intensa à heteronomia.

Voltando a George Steiner, na atribuição do doutoramento honoris causa pela Universidade de Lisboa em 2009, o ensaísta terminou o seu discurso com uma piada bem otimista. Deus resolve acabar com a humanidade de forma definitiva e em dez dias toda a espécie vai morrer afogada. Os homens, desesperados, vão ter com o seu rabi anunciando a sentença. Sereno, este responde-lhes: “Calma, calma, dez dias é tempo de sobra para aprender a respirar debaixo de água". Haverá quem profetize para este século o fim da universidade pública. Não é impossível que assim seja. Mas a essas profecias (geralmente autocumpridas) exige-se maior prudência. É que não há qualquer razão de natureza sociológica que nos leve a achar que não vai continuar a haver quem insista em aprender a respirar debaixo de água.

\section{Referências bibliográficas}

Almeida, João Ferreira de, e José Madureira Pinto (1975), “Teoria e investigação empírica em ciências sociais", Análise Social, IX (42-43), pp. 365-445.

Amaral, Alberto (2003), Avaliação, Revisão e Consolidação da Legislação do Ensino Superior, Matosinhos, CIPES-FUP.

Amaral, Alberto, Orlanda Tavares, e Cristina Santos (2012), "Higher education reform in Europe: an historical and comparative perspective of the new legal frameworks in Europe" em A. Curaj, P. Scott, P. Vlasceanu e Lesley Wilson (orgs.), European Higher Education at the Crossroads. Between the Bologna Process and National Reforms, Dordrecht, Heidelberga, Nova Iorque e Londres, Springer, pp. 655-673.

Barrias, Pedro (2013), A Nova Gestão Pública e as Universidades Fundacionais, Porto, Média XXI.

Bertolin, Julio Cesar G. (2011), “The quasi-markets in higher education: from the improbable perfectly competitive markets to the unavoidable State regulation", Educação e Pesquisa, 37 (2), pp. 237-247. 
Boden, Rebeca, e Maria Nedeva (2009), “Employing discourse: universities and graduate 'employability'”, Jornal of Education Policy, 15, pp. 37-54.

Bourdieu, Pierre (1984a), Questions de Sociologie, Paris, Les Editions de Minuit.

Bourdieu, Pierre (1984b), "Quelques propriétés des champs", em Pierre Bourdieu, Questions de Sociologie, Paris, Les Editions de Minuit.

Bourdieu, Pierre (1989), La Noblesse d'Etat, Paris, Les Editions de Minuit.

Bourdieu, Pierre (1992), "Le champ littéraire”, Actes de la Recherche en Sciences Sociales, 89, pp. 3-46.

Bourdieu, Pierre (2001), Razões Práticas. Sobre a Teoria da Acção, Oeiras, Celta Editora.

Bourdieu, Pierre (2011), "A génese dos conceitos de habitus e de campo", em Pierre Bourdieu, O Poder Simbólico, Lisboa, Edições 70.

Bourdieu, Pierre, Jean-Claude Chamboredon, e Jean-Claude Passeron (2010), O Ofício de Sociólogo, Rio de Janeiro, Editora Vozes.

Cabrito, Belmiro (2011), “Financiamento e privatização do Ensino Superior em Portugal: entre a Revolução de Abril e a Declaração de Bolonha", em Belmiro Cabrito e Vera Jacob (orgs.), Políticas de Financiamento e Acesso da Educação Superior no Brasil e em Portugal, Lisboa, Educa, pp. 45-59.

Cabrito, Belmiro, e Vera Jacob (2011), Políticas de Financiamento e Acesso da Educação Superior no Brasil e em Portugal. Tendências Atuais, Lisboa, Educa.

Canário, Rui (2005), O que É a Escola? Um Olhar Sociológico, Porto, Porto Editora.

Cerdeira, Luísa (2008), O Financiamento do Ensino Superior Português. A Partilha de Custos, Lisboa, Universidade de Lisboa, tese de doutoramento em Ciências da Educação.

Cerdeira, Luísa (2009), “Cost-sharing policy in the European higher education: a comparative perspective", Problems of Education in the 21st Century, 15 (15), pp. 60-77.

Cunha, L. A. (2006), “Autonomia universitária: teoria e prática”, em Hebe Vessuri (org.), Universidad e Investigación Científica: Convergencias y Tensiones, Buenos Aires, Clacso, pp. 13-31.

Drago, Ana (2005), Agitar antes de Ousar. O Movimento Estudantil "Antipropinas", Porto, Afrontamento.

Dréze, J., e J. Debelle (1983), Concepções da Universidade, Fortaleza, EdUFCE.

Friedman, Milton (2014), Capitalismo e Liberdade, Coimbra, Almedina.

Gibbons, Michael (1998), Higher Education Relevance in the 21st Century, Washington, World Bank.

Hayek, Friedrich (2010), O Caminho da Servidão, São Paulo, Instituto Ludwig von Mises Brasil.

Hood, Cristopher (1991), "A Public Management for all seasons?", Public Administration, 69, pp. 3-19.

Humboldt, W. (1997), “Sobre a organização interna e externa das instituições científicas superiores em Berlim", em G. Casper e W. Humboldt, Um Mundo sem Universidades?, Rio de Janeiro, EdUERJ.

Magalhães, António, e Alberto Amaral (2007), “Changing values and norms in Portuguese higher education", Higher Education Policy, 20, pp. 315-338.

Mineiro, João (2015), “Ciência, profissão e empregabilidade: três teses sobre a relação entre a sociologia e o mercado de trabalho", Sociologia Online - Revista da Associação Portuguesa de Sociologia, 8, pp. 97-110, disponível em: 
http://revista.aps.pt/cms/files/artigos_pdf/ART5555b2734c02f.pdf (última consulta em junho de 2016).

Neto, Mateus António da Silva (1999), Concepções de Universidade. Uma Perspectiva Fenomenológico-Existencial Hermenêutica, São Luís, EdiCEUMA.

Newman, John (1996), “A ideia de universidade”, em Frank M. Turner (org.), Newman e a Ideia de Universidade, Bauru, SP, EdUSC.

Oliveira, António Cândido, Paulo Peixoto, e Sílvia Silva (2014), O Papel dos Conselhos Gerais no Governo das Universidades Públicas Portuguesas. A Lei e a Prática, Braga, NEDAP/IUC.

Rubião, André (2013), A História da Universidade. Genealogia para Um Modelo Participativo, Coimbra, Almedina.

Santos, Boaventura de Sousa, e Noamar de Almeida Filho (2008), A Universidade no Século XXI. Para Uma Universidade Nova, Coimbra, Almedina.

João Mineiro. Doutorando e bolseiro de investigação, Socius-ISEG e CRIA-IUL, Avenida das Forças Armadas, Edifício IUL, 1649-026, Lisboa, Portugal. E-mail: joao.mineiro.6@gmail.com

Receção: 08-01-2016 Aprovação: 22-05-2016 
